\title{
Duplication of the spleen accompanied by multiple anomalies of the thorax and abdomen: a rare case
}

\author{
S. Sahin' ${ }^{1}$ A.H. Baykan² \\ ${ }^{1}$ Department of Radiology, Adiyaman Education and Research Hospital, Adiyaman, Turkey \\ 2Department of Radiology, Adiyaman University Faculty of Medicine, Adiyaman, Turkey
}

[Received: 28 October 2019; Accepted: 17 December 2019]

Duplication of the spleen, classified as a polysplenia syndrome, is a very rare anomaly. Polysplenia is a complex syndrome with a broad spectrum of abnormalities. Other abnormalities accompanying polysplenia have been previously reported. In this paper, we present a case of duplication of the spleen accompanied by multiple anomalies in the thorax and abdomen. (Folia Morphol 2020; 79, 4: 867-870)

Key words: spleen, duplication, computed tomography

\section{INTRODUCTION}

Duplication of the spleen is a rare seen anomaly which is classified in polysplenia syndrome. Polysplenia refers to the situation in which the splenic tissue is divided into two or more equal parts [4]. It is often associated with various visceral anomalies [4]. Polysplenia is a rare embryological disease reported in 1 in 250,000 people, resulting from failure in the development of normal asymmetry of left-right visceral organs [8]. Genetic studies showed that polysplenia is multifactorial inheritance [16]. Polysplenia is reported more frequently in women [1]. It must be distinguished from accessory spleen which defines the situation in which a normal sized spleen and one or more small spleen tissues are present [4]. Kim et al. [7] used the duplication of the spleen term to express similarly shaped splenic tissues that have their own arteries and veins.

In this paper, we present a case of duplication of the spleen accompanied by new thoracic and abdominal anomalies.

\section{CASE REPORT}

In April 2018, a 44-year-old female patient presented to the emergency department with sudden onset of left sided chest pain. She denies any fever, cough, shortness of breath. The patient had no pain with palpation and coughing. The physical exam was completely normal including auscultation of the heart and lungs. Vital signs were stable. Common causes of sudden chest pain were investigated (Table 1). Chest $\mathrm{X}$-ray was unremarkable. Electrocardiogram and cardiac enzymes were in the normal range. Echocardiographic measurements were within standard normal limits. Computed tomography (CT) angiography showed pseudocoarctation of the aorta characterised by kinking and post-stenotic dilatation at the isthmus level of the aorta (Fig. 1A, E) and dilated azygos vein (Fig. 1B, C). The position of the heart was normal.

Table 1. Differential diagnosis of diseases frequently seen at sudden onset chest pain

\begin{tabular}{l}
\hline Common causes of chest pain \\
\hline Acute coronary syndrome \\
Pericarditis \\
Aortic dissection \\
Pulmonary embolism \\
Oesophageal rupture \\
Pneumonia \\
Pleurisy
\end{tabular}




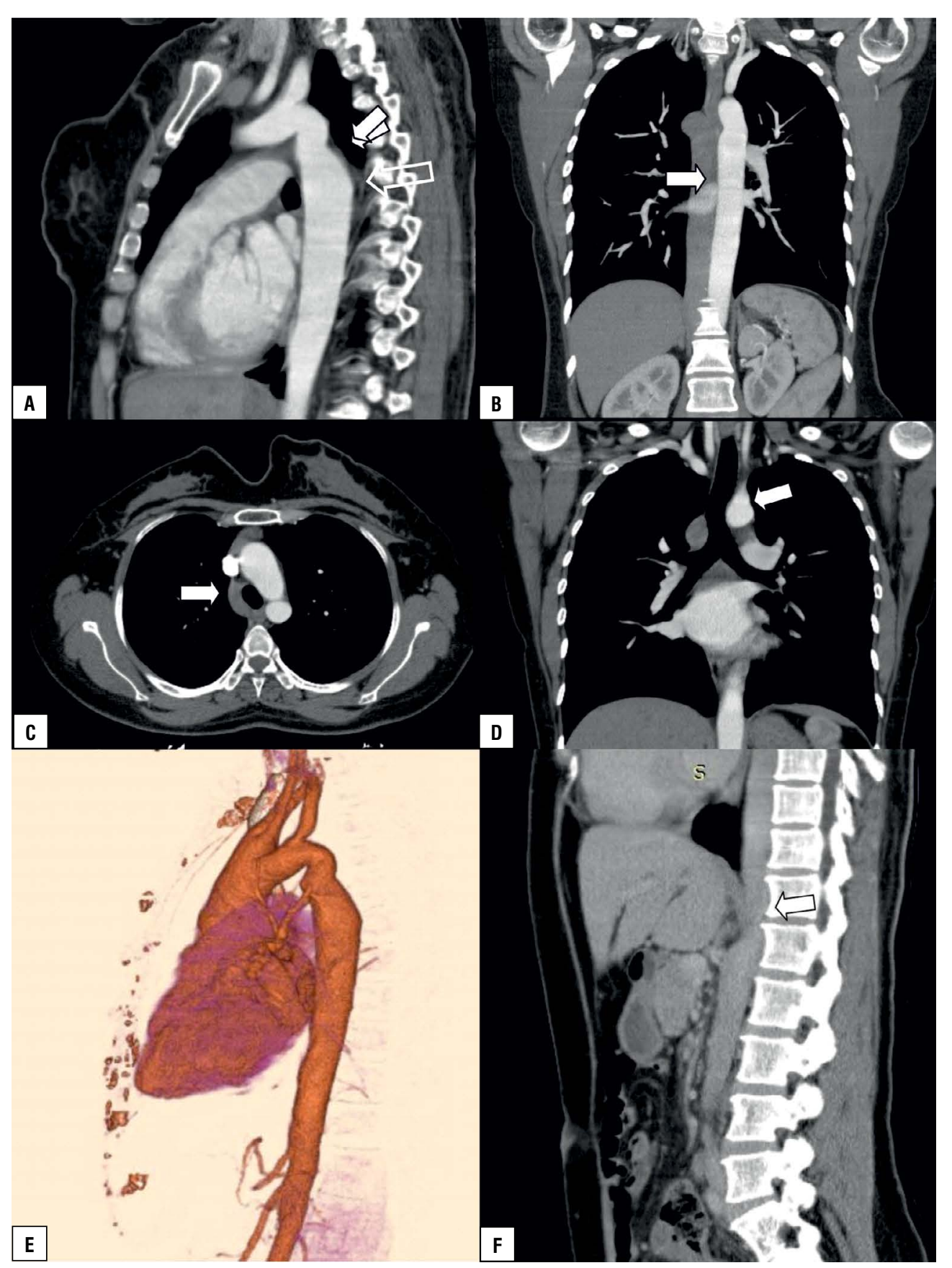

Figure 1. A. Sagittal reformed contrast-enhanced thorax computed tomography (CT) shows kink (arrow) and post-stenotic dilatation (hollow arrow) at the isthmus level of the aorta; B. Coronal reformed contrast-enhanced thorax CT shows dilated azygos vein (arrow); C. Dilated azygos vein (arrow) before joining the superior vena cava on axial contrast-enhanced thorax CT; D. Coronal reformed contrast-enhanced thorax CT shows compression of the trachea by the aorta; E. Volume rendering aortic pseudocoarctation in left lateral view; F. Sagittal reformed contrast-enhanced thorax CT with continuous inferior vena cava.

Indentation of the aorta to the trachea was observed (Fig. 1D). Both lungs were bilobulated. Inferior vena cava (IVC) showed continuity with the dilated azygos vein at the entrance into the thorax after the inclusion of the left retro-aortic renal vein and right renal vein (Fig. 1F). The hepatic veins were opened directly into the right atrium. At $\mathrm{CT}$ examination, contrast phase was not sufficient to evaluate pulmonary embolism. When D-dimer elevation and thrombosis consistent with acute deep vein thrombosis were detected in the left lower extremity veins, the patient was evaluated as pulmonary embolism and treated. 


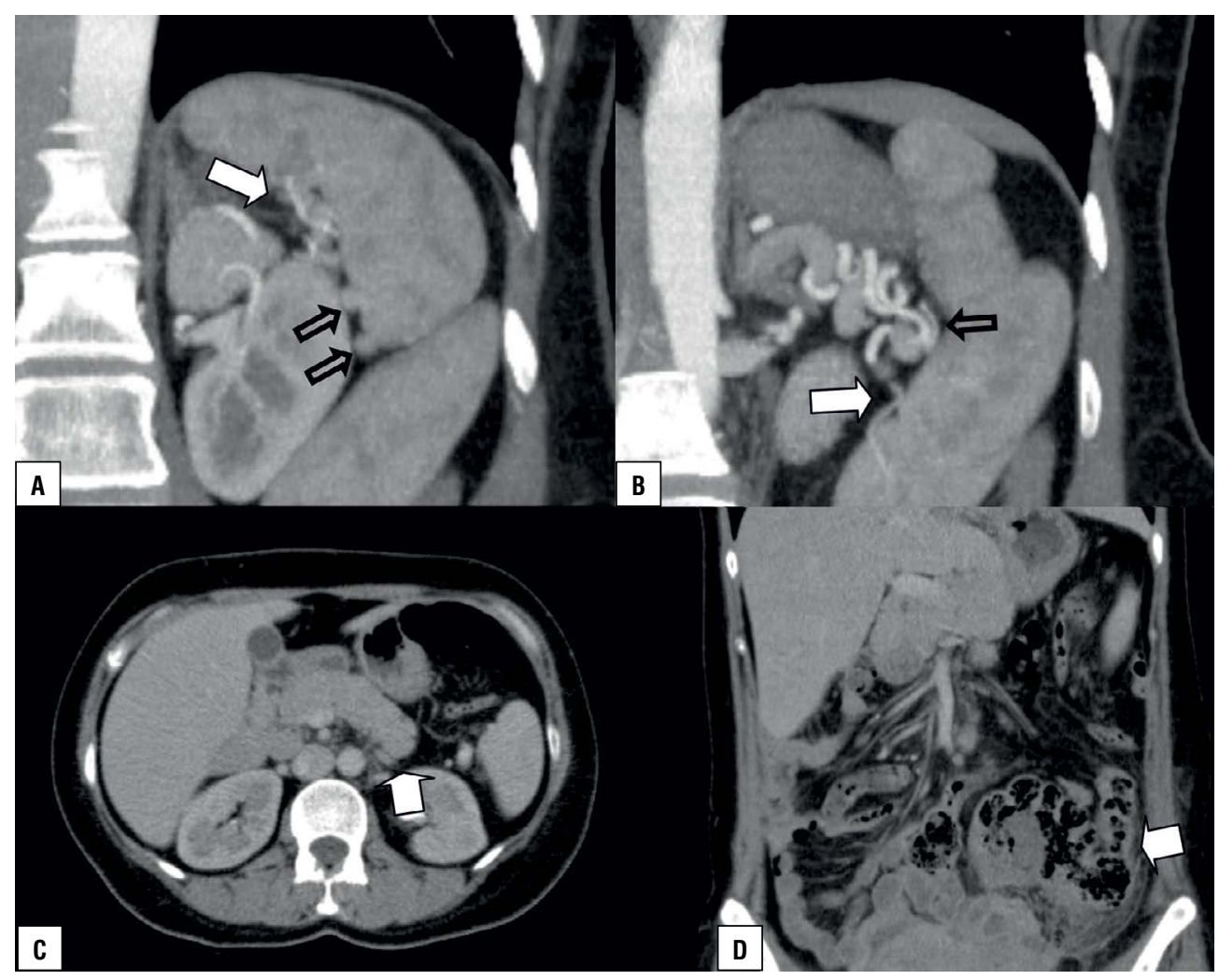

Figure 2. Duplication of the spleen; $\mathbf{A}$. The contrast-enhanced coronal abdominal computed tomography (CT) shows superior spleen and its own vascular structures (arrow) in CT maximum intensity projection images. Accessory spleens (hollow arrows) are also monitored; B. Inferiorly located spleen and vascular structures (arrow) are observed. Splenic artery branch from the lower spleen hilus feeding the lower pole of the upper spleen (hollow arrow); C. Short pancreas (arrow) on axial contrast enhanced abdominal CT; D. Coronal reformed contrast-enhanced abdominal CT shows that the colon segments are completely located on the left side of the abdomen (arrow).

She was admitted to our hospital with pelvic pain in September 2019. Physical examination revealed tenderness in the pelvic region. Complete blood count revealed leukocytosis and ultrasound shown a complicated cystic lesion in the left ovary. Abdominal contrast enhanced $\mathrm{CT}$ revealed a $4 \mathrm{~cm}$ large cyst in the left ovary and stranding of the surrounding fatty tissue so the patient was diagnosed as pelvic inflammatory disease. In addition, two spleens of $\sim 9 \times 4 \mathrm{~cm}$ and $\sim 9.5 \times 3.5 \mathrm{~cm}$ in size located in the superior and inferior aspects, respectively. There was a characteristic staining of a zebra pattern in the abdominal sections of the images. The two spleens had their own vascular structures (Fig. 2A, B). They were also in close proximity to each other, but had not merged. Both spleens were supplied from the splenic artery branches and their venous drainage was to the splenic vein. In our case, the splenic artery had emerged from the coeliac trunk and with significant tortuosity in the distal half, was sending the lateral branch to the superior spleen first. This side branch was then divided into end branches extending to the upper and middle portions of the upper spleen. The terminal part of the splenic artery was divided into two end branches feeding the upper and lower poles of the lower spleen and a third end branch feeding the lower pole of the upper spleen. The splenic vein first emerged from the spleen located on the lower side and then drained from the upper spleen and formed the superior mesenteric vein and portal vein. Unusually, the distal half of the splenic vein was tortuous.

Rather than the classic "J" shape, the pancreas was ovoid in appearance, with the body being thicker than the head. The pancreatic tail ended at the level of the medial half of the left kidney (Fig. 2C). The colon segments were located in the left half of the abdomen (Fig. 2D).

\section{DISCUSSION}

Duplication of the spleen can be confused with splenic cleft, splenic lobulation, and an accessory spleen. However, in cases with splenic duplication, 
both spleens have their own vascular structures, and both spleens do not merge with each other. This finding provides differentiation of splenic duplication from other splenic anomalies.

Duplication of the spleen was first described in 2009 by Kim et al. [7] on abdominal CT to investigate metastasis in a 71-year-old male patient with small cell lung cancer. This patient also had short pancreas and preduodenal portal vein. In our case, there is also a short pancreas which has also been reported in other polysplenia syndromes $[5,12,15]$. Later in 2013 , Sharma et al. [13] reported a 43-year-old male patient presenting with upper gastrointestinal bleeding. In this case, the reason of bleeding was the varicose veins due to the abnormal venous drainage of the upper part of the spleen to the gastric fundus veins. Endoscopy, endosonography, angiography and CT findings were reported without any additional visceral anomalies. Finally, in 2014, Paramasivam et al. [9] reported the cadaveric findings of a 60-year-old man.

Duplication of the spleen is classified in polysplenia syndrome with accompanying similar pathologies.

Gastrointestinal system anomalies, liver anomalies, and IVC anomalies have been described in patients with polysplenia [3]. In a study, 7 of 8 patients with polysplenia were reported to have continuous IVC with azygos vein [3]. Azygos continuation of the IVC is the most common anomaly seen in polysplenia syndromes [3]. The coexistence of aortic pseudocoarctation and polysplenia has also been previously reported $[2,11]$, which is consistent with the kink and post-stenotic dilatation observed at the aortic isthmus level in the current case. The left retro-aortic renal vein is usually isolated.

Embryologically, the left renal vein normally develops from inter-subcardinal anastomosis [6] while the retro-aortic vein develops from inter-supracardinal anastomosis and accompanies azygos continuation of IVC and polysplenia [14]. Bilobulated right lung has been described in patients with polysplenia and occurs in slightly more than half of the cases [10]. Polysplenia generally is associated with intestinal malrotation [3] and also in our case intestinal malrotation has been presented.

\section{CONCLUSIONS}

In conclusion, our case of duplication of the spleen showed similar aortic, IVC, pulmonary, pancreatic, and intestinal abnormalities to other polysplenia syndromes. The presence of multiple anatomical anomalies in these patient groups is important in the planning of surgical and interventional procedures in order to avoid undesirable outcomes.

\section{REFERENCES}

1. Applegate KE, Goske MJ, Pierce G, et al. Situs revisited: imaging of the heterotaxy syndrome. Radiographics. 1999; 19(4): 837-52; discussion 853, doi: 10.1148/radiographics.19.4.g99jl31837, indexed in Pubmed: 10464794.

2. Duarte R, Morais H. Aortic pseudocoarctation associated with polysplenia/heterotaxy syndrome. Rev Port Cardiol. 2015; 34(1): 73.e1-73.e3, doi: 10.1016/j. repc.2014.08.012, indexed in Pubmed: 25583627.

3. Fulcher AS, Turner MA. Abdominal manifestations of situs anomalies in adults. Radiographics. 2002; 22(6): 1439-1456, doi: 10.1148/rg.226025016, indexed in Pubmed: 12432114.

4. Griffiths JD, Marshall VC. Torsion of the spleen in the polysplenia syndrome. Aust N Z J Surg. 1984; 54(6): 571-573, doi: 10.1111/j.1445-2197.1984.tb05449.x, indexed in Pubmed: 6596079.

5. Herman TE, Siegel MJ. Polysplenia syndrome with congenital short pancreas. AJR Am J Roentgenol. 1991; 156(4): 799-800, doi: 10.2214/ajr.156.4.2003448, indexed in Pubmed: 2003448.

6. Kandpal H, Sharma R, Gamangatti S, et al. Imaging the inferior vena cava: a road less traveled. Radiographics. 2008; 28(3): 669-689, doi: 10.1148/rg.283075101, indexed in Pubmed: 18480478.

7. Kim SW, Shin HC, Kim IY, et al. Duplication of the spleen with a short pancreas. Br J Radiol. 2009; 82(975): e42-e43, doi: 10.1259/bjr/20162904, indexed in Pubmed: 19211901.

8. Low JP, Williams D, Chaganti JR. Polysplenia syndrome with agenesis of the dorsal pancreas and preduodenal portal vein presenting with obstructive jaundice: a case report and literature review. Br J Radiol. 2011; 84(1007): e217-e220, doi: 10.1259/bjr/27680217, indexed in Pubmed: 22011826.

9. Paramasivam V, Anand A, Shastri D, et al. Duplication of spleen A Rare Case Report. NJBMS. 2014; 4.

10. Peoples WM, Moller JH, Edwards JE. Polysplenia: a review of 146 cases. Pediatr Cardiol. 1983; 4(2): 129-137, doi: 10.1007/BF02076338, indexed in Pubmed: 6878069.

11. Rameshbabu CS, Gupta KK, Qasim M, et al. Heterotaxy polysplenia syndrome in an adult with unique vascular anomalies: case report with review of literature. J Radiol Case Rep. 2015; 9(7): 22-37, doi: 10.3941/jrcr.v9i7.2210, indexed in Pubmed: 26629295.

12. Sener RN, Alper H. Polysplenia syndrome: a case associated with transhepatic portal vein, short pancreas, and left inferior vena cava with hemiazygous continuation. Abdom Imaging. 1994; 19(1): 64-66, doi: 10.1007/BF02165866, indexed in Pubmed: 8161909.

13. Sharma $P$, Alkadhi $H$, Gubler $C$, et al. Splenic duplication: a rare cause of acute upper gastrointestinal bleeding. Abdom Imaging. 2013; 38(1): 163-166, doi: 10.1007/ s00261-012-9884-4, indexed in Pubmed: 22476371.

14. Tawfik AM, Batouty NM, Zaky MM, et al. Polysplenia syndrome: a review of the relationship with viscero-atrial situs and the spectrum of extra-cardiac anomalies. Surg Radiol Anat. 2013; 35(8): 647-653, doi: 10.1007/s00276013-1100-x, indexed in Pubmed: 23508931.

15. Wainwright $H$, Nelson $M$. Polysplenia syndrome and congenital short pancreas. Am J Med Genet. 1993; 47(3): 318-320, doi: 10.1002/ajmg.1320470304, indexed in Pubmed: 8135273.

16. Wolla CD, Hlavacek AM, Schoepf UJ, et al. Cardiovascular manifestations of heterotaxy and related situs abnormalities assessed with CT angiography. J Cardiovasc Comput Tomogr. 2013; 7(6): 408-416, doi: 10.1016/j. jcct.2013.11.008, indexed in Pubmed: 24331937. 